\title{
PREVENCION DE LA RUBEOLA RECOMENDACIONES DEL CDC. ATLANTA, EE. UU.
}

La novedad en la revisión de las recomendaciones del Comité para el empleo de la vacuna de la rubeola se centra en el énfasis sobre el incremento en la vacunación de las personas mayores, en particular de las mujeres en edad fértil, sin descuidar el programa de vacunación de los niños.

\section{INTRODUCCION}

La rubeola es una enfermedad eruptiva, común en la niñez, que debido a la variabilidad de sus signos y síntomas suele pasar inadvertida o no ser diagnosticada. Los signos más comunes (linfoadenopatías suboccipitales y retro-auriculares, artralgias, brote eritematoso pasajero y fiebre baja) pueden no ser reconocidos como indicadores de la enfermedad. Por otra parte, tampoco son infrecuentes los casos de infección sub-clínica. Algunas veces, particularmente en las mujeres, la rubeola es acompañada o seguida de poliartralgias y poliartritis transitorias. Raras veces se han comunicado casos de trombocitopenia o de complicaciones del sistema nervioso central.

En realidad, las consecuencias de mayor interés en la rubeola son las anomalías congénitas que resultan de la infección durante los primeros estadios del embarazo, especialmente en el primer trimestre. El principal objetivo de los programas de inmunización será entonces, la prevención de la infección fetal y del consecuente sindrome de la rubeola congénita.

Parece que la inmunidad post-infección sea de larga duración. No obstante, como ocurre en otras enfermedades virales, la re-exposición en condiciones naturales

* Traducido de: Morbidity and Mortality Weekly. February 6, $1981 / \mathrm{vol} .30 \mathrm{No} .4 .(37-42,47)$ con autorización del CDC Atlanta, EE. UU. puede llevar a una reinfección, sin manifestaciones clínicas ni viremia detectable. La única evidencia de la inmunidad es la presencia de los anticuerpos específicos. Se puede confiar en los laboratorios que realizan regularmente las determinaciones de anticuerpos, gracias a que los reactivos y las técnicas están perfectamente estandarizados.

Antes de la aparición de la vacuna en 1969 la mayoría de los casos de rubeola se presentaban en niños en edad escolar; ahora la mayoría de los casos ocurren en adolescentes y en adultos jóvenes. La incidencia en adolescentes y adultos jóvenes no ha disminuído en forma apreciable porque la vacuna se ha venido empleando primordialmente en niños preescolares y escolares.

A partir de 1976 más del 70\% de los casos se han presentado en persona de 15 o más años de edad, encontrándose en este grupo una susceptibilidad del 10 al 20 por ciento. Hasta finales de 1979 se habían distribuído en los Estados Unidos más de 98 millones de dosis de vacuna antirubeólica de virus vivos atenuados. La práctica de vacunar a los niños ha prevenido las epidemias, pero la enfermedad continúa siendo endémica en la población de adolescentes y de adultos jóvenes. Se continúa informando sobre brotes en los colegios y universidades, en las fuerzas armadas, en las oficinas de empleo y en los hospitales. Los datos sugieren la necesidad de combinar la vacunación de los niños con la de adolescentes y adultos susceptibles, para tratar de eliminar el sindrome de rubeola congénita.

\section{VACUNA ANTIRUBEOLICA DE VIRUS VIVOS}

La vacuna de virus vivos contra la rubeola distribuída formalmente en los Estados Unidos se prepara en cultivos de células 
humanas. Esta vacuna (RA 27/3) reemplazó en enero de 1979 a la vacuna HPV-77: De 5, producida en cultivos celulares de embrión de pato. Auncuando se han hecho estudios sobre su administración tanto intranasal como subcutánea, sólo se ha autorizado esta última vía. La vacuna se produce como monovalente (solo anti-rubeola) o en combinación: sarampión-rubeola (MR)y sarampiónpaperas-rubeola (MMR). Se recomienda a los trabajadores del sector salud el empleo de la vacuna MMR en los programas rutinarios de vacunación de niños y cuando quiera se necesite vacunar a personas susceptibles, tanto a rubeola como a sarampión y paperas.

Aproximadamente el 95\% de las personas susceptibles, de 12 o más meses de edad, que reciben una sola dosis de vacuna contra la rubeola, desarrollan anticuerpos, y puede esperarse en ellas una protección de larga duración o quizás de por vida, no solo contra la enfermedad sino también contra la viremia asintomática. Auncuando los títulos inducidos por la vacuna son por lo general menores que los inducidos por la infección, la inmunidad generada por la vacuna protege contra la enfermedad y contra la viremia después de la exposición natural.

La prueba de la inhibición de la hemaglutinación (HI) es la empleada con más frecuencia para detectar los anticuerpos en los controles de inmunidad contra la rubeola, sin embargo hay otras pruebas, tales como: hemaglutinación pasiva, hemólisis en gel o inmuno adsorción enzimática (ELISA). Ahora se cuenta con pruebas más sensibles que la HI. En efecto, en casi todos los individuos de una población de adultos cuya seroconversión post-vacunal parecía fallida, se detectaron anticuerpos cuando se examinaron más detalladamente por pruebas más sensibles. De un escaso número de niños que, habiendo hecho su seroconverción inicial, aparecieron luego como si hubieran perdido los anticuerpos en el curso de los nueve años de seguimiento, se detectaron éstos en casi todos los niños mediante pruebas más sensibles. De acuerdo con ello, cualquier cantidad de anticuerpos que se detecten, o la historia de una vacunación, es una evidencia presuntiva de inmunidad.
Algunas personas eliminan intermitentemente de la faringe pequeñas cantidades de virus entre 7 y 28 días después de haber sido vacunadas; sin embargo, el control de más de 1.200 contactos familiares susceptibles no demostró que hubiera habido transmisión de virus vacunal. Este dato sugiere que no hay riesgo al vacunar un niño susceptible cuya madre u otra mujer conviviente estén grávidas.

Todo título de anticuerpos detectables (sea que resulte por una vacunación o por una rubeola adquirida naturalmente), auncuando sea bastante bajo, protege contra la infección virémica subsecuente, incluida la llamada "reinfección" de las personas con bajos títulos de anticuerpos. Esto sugiere que las mujeres inmunes cuando se infectan durante la preñez no están en condiciones de infectar a sus fetos. Aún más, parece que por haber muy poca excreción faringea no habría riesgo para los contactos susceptibles en estos tipos de reinfección. Por los datos acumulados en la última década, el Comité no ve razonable el que se revacune a las personas cuyos títulos sean bajos en la prueba HI.

\section{EMPLEO DE LA VACUNA}

\section{Recomendaciones Generales}

La vacuna de la rubeola se recomienda para todos los niños, para muchos adolescentes y para algunos adultos, particularmente mujeres, a menos que haya una contraindicación específica. Al vacunar niños se les protege contra la enfermedad y se previene el que diseminen el virus. Al vacunar las mujeres susceptibles después de la pubertad se les confiere una protección individual contra las anomalías fetales. Al vacunar adolescentes y adultos, hombres y mujeres, en grupos de población tales como colegios, agencias de empleo o bases militares, se les protege contra la enfermedad y se reduce la posibilidad de epidemias.

\section{Dosis}

Se administra, por vía sub-cutánea, una sola dosis de $0,5 \mathrm{ml}$. de la vacuna reconstituída. 


\section{Personas en Riesgo}

La vacuna de virus vivos se recomienda para todos los niños de 12 o más meses de edad; en los menores de esta edad, la persistencia de los anticuerpos maternos puede interferir con la seroconversión. Cuando la vacuna de la rubeola forma parte de una combinación donde está incluída la vacuna contra el sarampión, la vacuna se hará en los niños de 15 o más meses de edad con el fin de lograr una máxima seroconversión en sarampión.

Los niños mayores que no hayan recibido la vacuna, deben vacunarse prontamente. Como la historia de haber enfermado no es un indicador seguro de inmunidad, todo niño debe ser vacunado a menos que exista alguna contraindicación.

Los servicios oficiales de salud deben dar los pasos pertinentes (incluyendo el desarrollo y obligatoriedad de los programas de inmunización) para asegurar que todos los escolares y todos los niños de las guarderías estén protegidos contra la rubeola, a menos que la vacunación esté contraindicada.

El Comité ha tomado en cuenta varias consideraciones en desarrollo de sus recomendaciones de vacunar contra la rubeola a las mujeres en edad fértil. Auncuando teóricamente hay riesgo en suministrar la vacuna durante el embarazo, todos los datos que se tienen sobre las vacunas anteriores y las actuales indican que el riesgo de teratogenicidad, si lo hay, es mínimo. Para octubre de 1980 el CDC había seguido, hasta el final del embarazo, a gestantes que, conocidas como susceptibles a la rubeola, habían sido vacunadas con vacuna de virus vivo, entre tres meses antes y tres meses después de la concepción. Noventa y tres de ellas recibieron vacuna HPV-77 o vacuna Cendehill y ocho recibieron vacuna RA 27/3. Ninguno de los niños tuvo malformaciones relacionadas con la infección por rubeola congénita, inclusive los de tres madres que desarrollaron infeccción presuntivamente subclínica por el virus de la vacuna. Con base en las experiencias conocidas hasta la fecha, el riesgo teórico estimado (según la distribución binomial) de manifestaciones serias atribuidas a la vacuna contra la rubeola, es de 0 a $4 \%$.

Auncuando la experiencia con la vacuna RA $27 / 3$ es más limitada que la que se tiene con otras vacunas, del material de los abortos de 15 mujeres susceptibles que fueron vacunadas con RA $27 / 3$ durante la gestación, no se aislaron virus vacunales como sí ocurrió en 17 de $85(20 \%)$ que en iguales circunstancias habián recibido vacuna HPV-77 o vacuna Cendehill. Esto aporta una evidencia adicional que la vacuna RA $27 / 3$ no conlleva un riesgo de teratogenicidad mayor que el de las vacunas HPV-77 y Cendehill.

Por lo anterior, el Comité conceptúa que la vacunación antirubeola durante la gravidéz no es una razón para recomendar como rutina el aborto. Auncuando la decisión final debe quedar a cargo de la paciente y de su médico, el Comité cree que el riesgo de malformaciones asociadas con la vacuna es tan bajo que se hace despreciable.

La continua ocurrencia de casos de enfermedad en mujeres en su etapa de fecundidad y la evidencia creciente de la poca o ninguna teratogenicidad de la vacuna, indican claramente que debe incrementarse la vacunación de las mujeres susceptibles, adolecentes y adultas, durante su edad fértil.

Sin embargo, por el riesgo teórico para el feto, las mujeres en edad fértil, solo deben vacunarse cuando se asegure que no están embarazadas y se les haya aconsejado que eviten el embarazo hasta por tres meses después de vacunadas. En vista de la importancia que tiene la protección de este grupo contra la rubeola, en los programas de inmunización se debe tener la razonable precaución de incluír el interrogatorio de la mujer sobre su estado gestacional, excluir de la vacunación a la mujer embarazada e informar a las demás sobre el riesgo teórico.

En la vigilancia continuada de la rubeola debe hacerse énfasis en la vacunación de los individuos susceptibles que han cursado la escuela superior. Los servicios militares han institucionalizado de rutina la vacunación 
para sus reclutas, tanto hombres como mujeres. Las instituciones educacionales o de adiestramiento, facultades y universidades, deben considerar muy seriamente la inmunidad contra la rubeola en el personal que aspira a ser admitido como estudiante o como empleado; por ejemplo, pueden exigir una prueba serológica positiva o el certificado de vacunación. Todo empleado, exceptuando las mujeres gestantes, de quien no se tenga la certeza de inmunidad debe ser vacunado, a menos que haya alguna contraindicación. El personal de salud debe revisar muy cuidadosamente el estado inmunitario contra la rubeola de los adultos jóvenes y vacunar aquellos que no tengan inmunidad documentada. Para proteger a las pacientes susceptibles y al personal de empleadas, las personas, hombres y mujeres, que trabajen en hospitales y clínicas donde pueden contraer la rubeola a partir de pacientes infectados, y quienes, estando infectados pueden transmitirla a pacientes embarazadas, deben ser vacunados.

Cuando se cuente con laboratorios prácticos y seguros, podrán hacerse pruebas serológicas a las mujeres en edad fértil con el fin de conocer su susceptibilidad y determinar si requieren vacunación. Las pruebas para detectar anticuerpos durante el examen premarital rutinario identificaron a muchas mujeres susceptibles, antes del embarazo. El control prenatal se recomienda como medida de gran valor para identificar a aquellas mujeres que deben ser vacunadas, tan pronto como el hijo nazca. La lactancia materna no es una contraindicación para la vacunación post-partum, aúncuando el virus pueda pasar a la leche y así el niño pueda infectarse. Sin embargo el establecer como rutina las pruebas serológicas para determinar la susceptibilidad de toda mujer en edad fértil, con el fin de vacunar sólo a las susceptibles, es costoso e inoperante en algunas áreas. El Comité conceptúa que se justifica vacunar, sin previa prueba serológica, a toda mujer no embarazada sin antecedentes de vacunación.

La toma y almacenamiento de una muestra de suero en el momento de la vacunación podría servir posteriormente para determi- nar, en caso de que la mujer vacunada hubiera entrado en embarazo en los días de esta vacunación, si para entonces estaba inmune. No obstante, el almacenamiento de una muestra de suero no se considera indispensable. El Comité considera que la vacunación de mujeres en edad fértil, de quienes se ignora que sean inmunes, es importante para una prevención más efectiva del síndrome de la rubeola congénita. Esta política debe ser promovida en todos los sitios que tengan que ver con el cuidado de la mujer fértil, incluidos colegios y escuelas, instituciones militares, hospitales, clínicas de planeación familiar, consultorios médicos y demás.

\section{Personas Expuestas a la Enfermedad}

Uso de la Vacuna después de la Exposición:

No hay evidencia que indique que el suministro de vacuna de virus vivo de rubeola, después de la exposición, pueda prevenir la enfermedad o que sea peligroso el vacunar a una persona que esté incubando la enfermedad. Como un simple contacto puede no causar la infección, pero la vacunación post-exposición si protege al individuo contra exposiciones futuras, se recomienda la vacunación, a menos que haya contraindicaciones.

Uso de la Inmunoglobulina Humana (IG), (antes llamada inmuno sero globulina ISG) después de la exposición:

La IG suministrada después de la exposición, puede no prevenir la infección ni la viremia, pero si modificar o suprimir los síntomas. No se recomienda el uso rutinario de IG para la profilaxis post-exposición en los comienzos de la gravidéz. (De las mujeres que han recibido IG muy poco después de la exposición, han nacido niños con rubeola congénita). La única circunstancia en la cual la IG podría ser útil, ocurre cuando una mujer embarazada que ha estado expuesta a la rubeola, se niega rotundamente a interrumpir el embarazo.

\section{Administración Reciente de IG}

La vacunación debe ser pospuesta, hasta nor tres meses, en las personas que han 
recibido IG, por cuanto estos anticuerpos pueden interferir con la respuesta a la vacuna. Sin embargo, la administración previa de inmunoglobulina (Humana) antiRho (D) o de productos sanguíneos, no es una contraindicación para la vacunación postpartum. En este caso, a quienes hayan recibido globulina o productos sanguíneos se les hará una prueba serológica entre 6 a 8 semanas después de la vacunación, para asegurarse si hubo o no conversión. En otros vacunados no es necesario buscar por el laboratorio la seguridad en la conversión.

\section{EFECTOS COLATERALES Y REACCIONES ADVERSAS}

A veces se presentan en los niños efectos colaterales por la vacuna, tales como rash y linfadenopatías. En amplias experiencias de campo, se ha visto que cerca de un $40 \%$ de los vacunados presentan dolores articulares, especialmente de las pequeñas articulaciones periféricas; las artritis francas solo han sido comunicadas para menos del $1 \%$ de la población vacunada. Las artralgias y las artritis pasajeras son más comunes y suelen ser más severas en las mujeres susceptibles que en los niños. Los síntomas articulares o los dolores no relacionados con las articulaciones o las parestesias, comienzan generalmente entre 7 y 21 días después de la vacunación, persisten por 1 a 3 días y rara vez recurren. Los adultos que presentan problemas articulares, por rareza tienen que interrumpir su actividad en el trabajo. Es muy probable que los pocos casos de persistencia o recurrencia de los signos y síntomas articulares, sean debidos a enfermedades concomitantes y no realmente a complicaciones por la vacuna. También son raros los casos de fenómenos neuríticos periféricos, transitorios, así como las parestesias y los dolores en brazos y piernas. Solo se han comunicado efectos colaterales en los susceptibles vacunados. No hay un incremento en el riesgo de estos efectos, en las personas que ya tienen inmunidad cuando se vacunan.

Aun cuando la vacuna es inócua y efectiva para toda persona de 12 o más meses de edad, no se conoce muy bien su inocuidad para el feto. En todo caso, aún cuando el riesgo parece mínimo, no se debe vacunar a la mujer embarazada, por el riesgo teórico de las anomalías fetales producidas por el virus de la vacuna (Véase Personas en Riesgo).

\section{PRECAUCIONES Y CONTRAINDICACIONES}

\section{Embarazo}

No se debe suministrar vacuna a la mujer gestante. Sí se vacuna una mujer grávida o sí queda embarazada en los tres meses subsiguientes a la vacunación, debe ser informada sobre el riesgo teórico para el feto. Como se anotó antes, la vacunación antirubeola durante el embarazo, no es una indicación de rutina para la interrupción del embarazo. Los casos de vacunación durante el embarazo deben ser comunicados a los departamentos oficiales de salud.

\section{Enfermedad Febril}

Las personas con enfermedad febril no deben ser vacunadas sino cuando se hayan recuperado. No obstante, las enfermedades menores, como las infecciones del tracto respiratorio alto, no contraindican la vacunación.

\section{Alergias}

No se ha comunicado asociación entre la vacuna de rubeola de virus vivo y reacciones alérgicas. Esta no contiene penicilina. Sin embargo, la vacuna lleva trazas de neomicina a la cual puede ser alérgico el paciente. Quienes administran la vacuna deben ser muy cuidadosos en seguir las indicaciones del producto, para decidir que paciente con antecedentes de alérgia a la neomicina puede ser vacunado sin riesgo.

\section{Inmunidad Alterada}

Teóricamente la replicación del virus de vacuna de la rubeola puede potenciarse en pacientes con enfermedades inmunodeficientes y por la supresión de la respuesta inmune que ocurre en leucemias, linfómas o enfermedades malignas generalizadas o aquellas resultantes de la terapia con corticosteroides, drogas alquilantes, antime- 
tabólitos o radiaciones. Los pacientes en estas condiciones no deben recibir la vacunación antirubeola de virus vivos.

\section{Administración Simultánea de \\ Ciertas Vacunas de Virus Vivos}

Veánse las "Recomendaciones Generales sobre Inmunización" MMWR 1980; 29: $76,81-3$.

\section{CONDUCTA ANTE BROTES EPIDEMICOS}

Para controlar brotes epidémicos, se vacunarán prontamente todas las personas susceptibles en riesgo; las mujeres en edad fértil sólo se vacunarán cuando no estén embarazadas y se les haya advertido que deben evitar el embarazo durante los siguientes tres meses. (Véase personas en riesgo).

\section{VIGILANCIA EPIDEMIOLOGICA}

Se consideran de mucha importancia para el control de la rubeola, la seguridad diagnóstica y la pronta información a las autoridades de Salud sobre casos de rubeola, de sospecha de rubeola, de sindromes congénitos y de complicaciones por la vacuna. Aun más, todo caso de anomalía en el recién nacido, en el cual se sospecha que la rubeola tuvo papel causal, debe ser estudiado cuidadosamente e informado a las autoridades de salud.

\section{BIBLIOGRAFIA}

1. Bernstain DI, Ogra Pl. Fetomaternal aspects of immunization with RA $27 / 3$ live attenuated rubella virus vaccine during pregnancy. J Pediatr; 1980. 97: 467.

2. Buimovici-Klein E, Hite RL, Byrne $T$, Cooper LZ. Isolation of rubella viruses in milk after post-partum immunization. J. Pediatr; 1977. 91: 939.

3. Cooper LZ, Krupman S. The rubella problem. DM. 1969; Feb: 3-38.

4. CDC. Rubella-United States. MMWR. 1977$1980 ; 29: 378$.
5. Farquhar JD. Followup on rubella vaccinations and experience with sub-clinical reinfection. J Pediatr. 1972; 81: 460.

6. Furukuwa T, Miyata T, Kondo K. Kunok, Isomura S, Takekoshi T. Clinical Trials of RA 27/3 (Wistar) rubella vaccine in Japan. Am J Dis Child; 1969; 262.

7. Hayden GF, Herrmann KL, BuimoviciKlein E, Weiss KE, Nieberg PI, Michell JE. Subclinical congenital rubella infection associated with maternal rubella vaccination in aerly pregnancy. J. Pediatr; 1980; 97: 869 .

8. Herrmann KL, Halsted SB, BrandlingBennett AD, Witta JJ, Wiebeng NH, Eddins DL.Rubella immunization. Peristence of antibody 4 years after a large scale field trial. JAMA; $1976 ; 235-2201$.

9. Hillary IB, Griffith AH. Persistence of antibody 10 years after vaccination with Wistar RA $27 / 3$ strain live attenuated rubella vaccine. $\mathrm{Br}$. Med J; 1980; 224: 1580 .

10. Horstmann D. Controlling rubella: problems and perspective. Ann Intern Med; $1975 ; 83: 412$.

11. Klein EB, Byrne T, Cooper LZ. Neonatal rubella in a breast-fed infant after postpartum maternal infection. J. Pediatr; 1980; 97: 774 .

12. Krugman S. Present status of measles and rubella immunization in the United States: a medical progress report. J. Pediatr. $1977 ; 90: 1$.

13. Landes RD, Bass LW, Millunchick W, Oetgen WJ. Neonatal rubella following postpartum maternal immunization. J Pediatr; $1980 ; 97$ : 465.

14. Marymont JH, Herrmann KL. Rubella in pregnancy; review of current problems. Postgrad Med; 1974; 56: 167.

15. McLaughlin MC, Gold LH. The New York rubella incident; a case for changing hospital policy regarding rubella and immunization. Am J Public Health; 1979; 69:287 
16. Polk BF, White JA, DeGirolami PC, Modlin JF. An outbreak of rubella among hospital personnel. N Engl J Med; 1980; 303: 541.

17. Preblud SR, Serdula MK, Frank JA, Brandling-Bennett $\mathrm{AD}$, Hinman AR. Rubella vaccination in the United States: a tenyear review. Epidemiologic Reviews; 1980; 2: 171.
18. Weibel RE, Buynak EB, Mclean AA, Roehm RR, Hillem an MR. Persistence of antibody in human subjects 7 to 10 years following administration of combined live attenuated measles, mumps, and rubella virus vaccines. Proc Soc Exp Biol Med; 1980; 165: 260 . 